\title{
Steroid and xenobiotic receptor and vitamin D receptor crosstalk mediates CYP24 expression and drug-induced osteomalacia
}

\author{
Changcheng Zhou, ${ }^{1}$ Mahfoud Assem, ${ }^{2}$ Jessica C. Tay, ${ }^{1}$ Paul B. Watkins, ${ }^{3}$ Bruce Blumberg, ${ }^{4}$ \\ Erin G. Schuetz, ${ }^{2}$ and Kenneth E. Thummel ${ }^{1}$

\begin{abstract}
'Department of Pharmaceutics, University of Washington, Seattle, Washington, USA. ${ }^{2}$ St. Jude Children's Research Hospital, Memphis, Tennessee, USA. ${ }^{3}$ Department of Medicine, Division of Hepatology, University of North Carolina (UNC), Chapel Hill, North Carolina, USA.
\end{abstract} \\ ${ }^{4}$ Department of Developmental and Cell Biology, University of California, Irvine, California, USA.
}

\begin{abstract}
The balance between bioactivation and degradation of 1,25-dihydroxyvitamin $D_{3}\left[1,25(\mathrm{OH})_{2} \mathrm{D}_{3}\right]$ is critical for ensuring appropriate biological effects of vitamin D. Cytochrome P450, family 24-mediated (CYP24-mediated) 24-hydroxylation of $1,25(\mathrm{OH})_{2} \mathrm{D}_{3}$ is an important step in the catabolism of $1,25(\mathrm{OH})_{2} \mathrm{D}_{3}$. The enzyme is directly regulated by vitamin $\mathrm{D}$ receptor (VDR), and it is expressed mainly in the kidney, where VDR is also abundant. A recent report suggests that activation of steroid and xenobiotic receptor (SXR) also enhances the expression of CYP24, providing a new molecular mechanism of drug-induced osteomalacia. However, here we showed that activation of SXR did not induce CYP24 expression in vitro and in vivo, nor did it transactivate the CYP24 promoter. Instead, SXR inhibited VDR-mediated CYP24 promoter activity, and CYP24 expression was very low in tissues containing high levels of SXR, including the small intestine. Moreover, $1,25(\mathrm{OH})_{2} \mathrm{D}_{3^{-}}$ induced CYP24 expression was enhanced in mice lacking the SXR ortholog pregnane X receptor, and treatment of humans with the SXR agonist rifampicin had no effect on intestinal CYP24 expression, despite demonstration of marked CYP3A4 induction. Combined with our previous findings that CYP3A4, not CYP24, plays the dominant role in hydroxylation of $1,25(\mathrm{OH})_{2} \mathrm{D}_{3}$ in human liver and intestine, our results indicate that $S X R$ has a dual role in mediating vitamin $\mathrm{D}$ catabolism and drug-induced osteomalacia.
\end{abstract}

\section{Introduction}

Vitamin D exerts important biological functions in the maintenance of calcium homeostasis and in the development and maintenance of bones. Its active metabolite, 1,25-dihydroxyvitamin $\mathrm{D}_{3}$ $\left[1,25(\mathrm{OH})_{2} \mathrm{D}_{3}\right]$, elicits most of its effects through activation of the vitamin D receptor (VDR) $(1,2)$. VDR is a ligand-dependent transcription factor belonging to the nuclear receptor superfamily. After the binding of $1,25(\mathrm{OH})_{2} \mathrm{D}_{3}$ or other VDR ligands, VDR forms a heterodimer with the retinoid $X$ receptor (RXR) and associates with vitamin D-response elements (VDREs) on target genes. It can then either positively or negatively affect the expression of its target genes $(3,4)$. Bioactivation of vitamin D involves the sequential actions of two 25-hydroxylase enzymes (cytochrome P450, family 27A [CYP27A] and CYP2R1) in the liver and 1-hydroxylase enzyme (CYP27B) in the kidney, leading to the synthesis of hormonally active $1,25(\mathrm{OH})_{2} \mathrm{D}_{3}(3,5) .1,25(\mathrm{OH})_{2} \mathrm{D}_{3}$ is catabolized by CYP2 4 (also known as 25-hydroxyvitamin D 24-hydroxylase) in the kidney, which is followed by sequential metabolism, yielding the terminal product calcitroic acid $(6,7)$. It also undergoes CYP3A4-dependent 23- and 24-hydroxylations in the liver and small intestine (8).

Nonstandard abbreviations used: $1,25(\mathrm{OH})_{2} \mathrm{D}_{3}, 1,25$-dihydroxyvitamin $\mathrm{D}_{3}$; $\mathrm{CAR}$, constitutive androstane receptor; CLOT, clotrimazole; CYP, cytochrome P450; CYP24, cytochrome P450, family 24; OC, osteocalcin; PCN, pregnenolone $16 \alpha$-carbonitrile; PXR, pregnane X receptor; RIF, rifampicin; QRT-PCR, quantitative real-time PCR; RU486, mifepristone; RXR, retinoid X receptor; SPP, osteopontin; SXR, steroid and xenobiotic receptor; VDR, vitamin D receptor; VDRE, vitamin D-response element.

Conflict of interest: B. Blumberg is coinventor of several patents related to SXR-PXR, which are under the control of the Salk Institute for Biological Studies and for which he receives occasional royalty payments.

Citation for this article: J. Clin. Invest. 116:1703-1712 (2006). doi:10.1172/JCI27793.
The balance between bioactivation and degradation of $1,25(\mathrm{OH})_{2} \mathrm{D}_{3}$ is critical for ensuring appropriate biological effects and is tightly controlled in vivo. For example, elevated levels of parathyroid hormone associated with low-calcium states function to upregulate CYP27B and downregulate CYP24 enzymes. This increases plasma and cellular levels of $1,25(\mathrm{OH})_{2} \mathrm{D}_{3}$ to correct for calcium deficiency. In turn, $1,25(\mathrm{OH})_{2} \mathrm{D}_{3}$ shows feedback regulation of its own synthesis by suppressing CYP27B and upregulating CYP24 expression via activation of $\operatorname{VDR}(2,9,10)$. CYP24-mediated 24-hydroxylation of $1,25(\mathrm{OH})_{2} \mathrm{D}_{3}$ is a critical step in the catabolism of $1,25(\mathrm{OH})_{2} \mathrm{D}_{3}$ and appears to be responsible for controlling intrarenal and systemic $1,25(\mathrm{OH})_{2} \mathrm{D}_{3}$ levels. CYP24 is directly regulated by VDR, and it is expressed mainly in the kidney, where VDR is also abundant. Although there is also a relatively high level of VDR expression in the small intestine, constitutive CYP24 expression in this tissue is very low or undetectable, in contrast to that in the kidney (8).

It is well recognized that long-term therapy with some antiepileptic drugs, including phenobarbital, phenytoin, and carbamazepine and the antimicrobial agent rifampicin (RIF), can cause a metabolic bone disease - osteomalacia (11-15). The side effects observed in those patients are very similar to vitamin $\mathrm{D}$ deficiency, and induction of the catabolism of $1,25(\mathrm{OH})_{2} \mathrm{D}_{3}$ is thought to contribute to this deleterious side effect. Although it has been studied extensively, the molecular mechanism of drug-induced osteomalacia remains unclear (11). Interestingly, many (but not all) of the drugs that cause osteomalacia are able to activate another nuclear receptor - steroid and xenobiotic receptor (SXR; also known as pregnane $X$ receptor [PXR], PAR, and NR1I2) (16-18). SXR is expressed at high levels in the liver and small intestine, where it acts as a xenobiotic sensor that regulates the expression of 
A
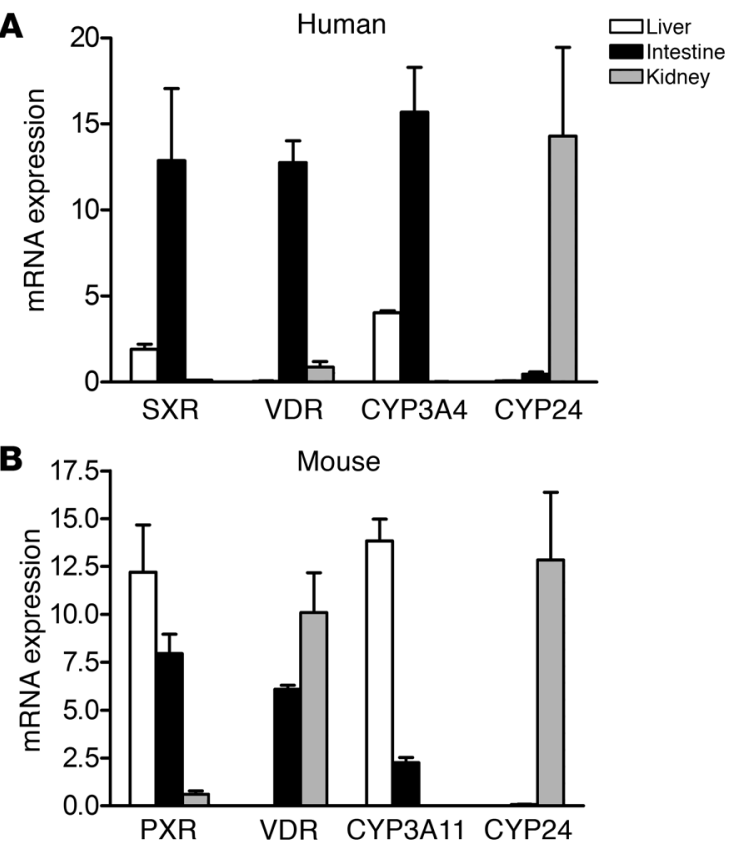

CYP enzymes such as CYP3A4 and CYP2C8; conjugation enzymes such as UGT1A1; and ABC family transporters such as MDR1 and MRP2 (19). SXR is thus a master regulator of xenobiotic clearance, coordinately controlling steroid and xenobiotic metabolism (20, 21). SXR is also expressed at much lower levels in other tissues such as kidney and normal and neoplastic breast tissue, although no function at these tissues has yet been described $(22,23)$.

A recent report by Pascussi et al. provided a new mechanism for drug-induced osteomalacia, suggesting that activation of SXR can enhance the expression of the VDR target gene, CYP24 (24). Under this scenario, induction of CYP24 would increase the catabolism of $1,25(\mathrm{OH})_{2} \mathrm{D}_{3}$ and therefore might lead to drug-induced osteomalacia. However, their model is of questionable significance with regard to the physiological functions of CYP24 in vivo, given that CYP24 is found primarily in the kidney, where SXR is expressed at very low levels. In addition, CYP24 is expressed at very low levels in liver and intestine, where SXR is abundant (8). This suggests that enhanced CYP24 expression may not play a role in the development of osteomalacia following long-term treatment with SXR activators.

In order to better understand the mechanism of drug-induced osteomalacia, we investigated the impact of SXR activation on CYP24 and CYP3A4 gene expression in vitro and in vivo. We report that activation of SXR neither transactivated the CYP24 promoter nor induced CYP24 expression. Instead, SXR inhibited VDR-mediated CYP2 4 promoter activity, and $1,25(\mathrm{OH})_{2} \mathrm{D}_{3}$-induced CYP24 expression was enhanced in mice lacking the SXR ortholog PXR. Combined with our previous findings that CYP3A4, not CYP24, dominated the hydroxylation of $1,25(\mathrm{OH})_{2} \mathrm{D}_{3}$ in human liver and intestine (8), our results indicate that SXR plays a dual role in mediating vitamin $\mathrm{D}$ catabolism and drug-induced osteomalacia. It upregulates CYP3A4 expression while repressing CYP24 expression in the liver and intestine.

\section{Results}

Expression of $S X R / P X R, V D R$, and their target genes in various tissues. To elucidate the roles of SXR and VDR in the regulation of

\section{Figure 1}

Expression of SXR/PXR, VDR, and their target genes in various tissues. (A) Total RNA was isolated from human liver, intestine, and kidney tissues $(n=3)$, and the expression of SXR, VDR, CYP3A4, and CYP24 was analyzed by QRT-PCR. (B) Total RNA was isolated from mouse liver, intestine, and kidney tissues $(n=3)$, and the expression of PXR, VDR, CYP3A11, and CYP24 was analyzed by QRT-PCR.

CYP24 expression, we first examined the levels of SXR/PXR and VDR mRNA and of their target genes - CYP3A4/CYP3A11 and CYP24 - in human and mouse liver, kidney, and small intestine. Gene expression was measured by quantitative real-time PCR (QRT-PCR) and is summarized in Figure 1. Consistent with previous reports (16), SXR/PXR was mainly expressed in the liver and intestine and found only at very low levels in kidney. In contrast, VDR was expressed mainly in the kidney and intestine at high levels but was almost undetectable in the liver. CYP3A4/CYP3A11 and CYP24, important enzymes involved in vitamin D metabolism, were expressed with distinctly different patterns. CYP3A4/ CYP3A11 was mainly expressed in the human and mouse liver and intestine, where SXR/PXR mRNA was also abundant. However, CYP24 expression was detected primarily in the kidney and minimally in the intestine, particularly in humans, and this pattern was not consistent with the high level of VDR expression in both kidney and intestine. VDR and CYP24 mRNA were almost undetectable in the liver.

$1,25(\mathrm{OH})_{2} \mathrm{D}_{3}$ but not SXR ligands induce CYP24 gene expression in buman intestinal cells and primary hepatocytes. The divergent patterns of SXR and CYP24 expression observed in kidney, intestine, and liver were at odds with the recent report that CYP24 expression is upregulated by SXR activators and that SXR directly regulates CYP24 promoter activity (24). To address this discrepancy, we tested whether SXR ligands induce CYP24 gene expression in primary hepatocytes. Human primary hepatocytes from 2 different donors were treated with various concentrations of $1,25(\mathrm{OH})_{2} \mathrm{D}_{3}$ and $10 \mu \mathrm{M}$ of 3 different SXR ligands, RIF, mifepristone (RU486), and clotrimazole (CLOT). Total RNA was isolated 24 hours later and QRT-PCR was performed to quantitate gene expression. As expected, the SXR ligands and $1,25(\mathrm{OH})_{2} \mathrm{D}_{3}$, were able to induce CYP3A4 gene expression, which is consistent with previous reports (25, $26)$. Among the 3 SXR ligands studied, RIF was the most potent inducer of CYP3A4, which is also consistent with our previous results (27). However, we found that activation of SXR by known agonists did not induce CYP24 gene expression in human primary hepatocytes (Figure 2, A and B), in contrast to the results of Pascussi et al. (24), Interestingly, $1,25(\mathrm{OH})_{2} \mathrm{D}_{3}$, stimulated CYP24 transcription in a dose-dependent manner, despite the very low levels of VDR mRNA. Levels of CYP24 mRNA were increased by

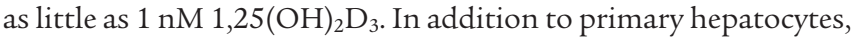
we also used 2 different intestinal cell lines, LS180 and Caco-2, to further test the ability of SXR to induce CYP24 expression. SXR was found at high levels in LS180 cells but at almost undetectably low levels in Caco- 2 cells, and VDR was expressed in both cell lines (data not shown), as reported previously (25). As shown in Figure 2, SXR ligands induced CYP3A4 gene expression in LS180 cells, but not in Caco- 2 cells, consistent with the lack of SXR expression. In contrast, $1,25(\mathrm{OH})_{2} \mathrm{D}_{3}$ induced CYP3A4 expression in both cell lines, consistent with the demonstrated role of VDR in intestinal CYP3A4 regulation. None of the SXR ligands affected CYP24 gene 
A

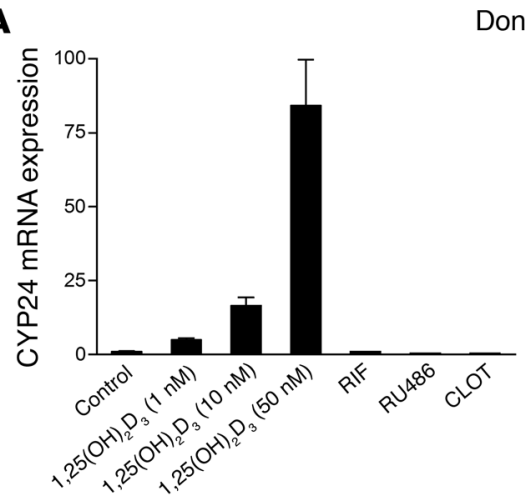

B

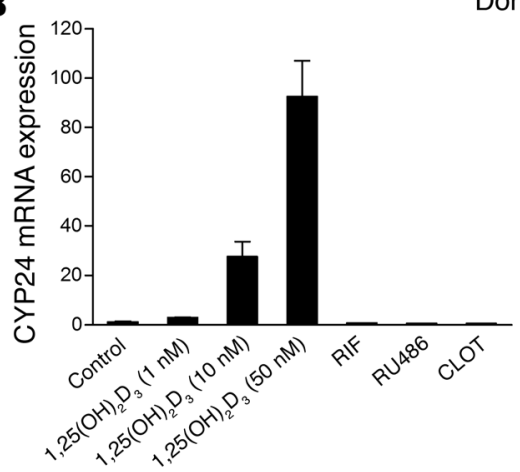

C

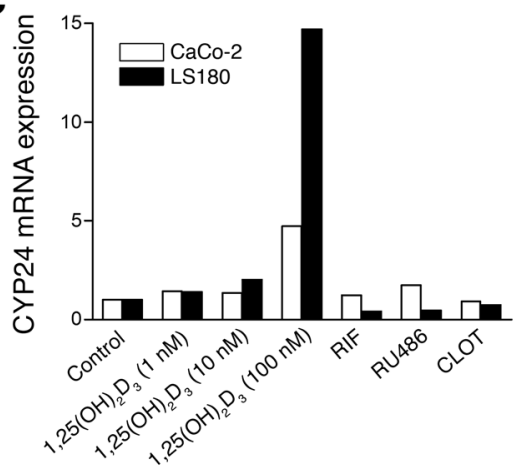

D

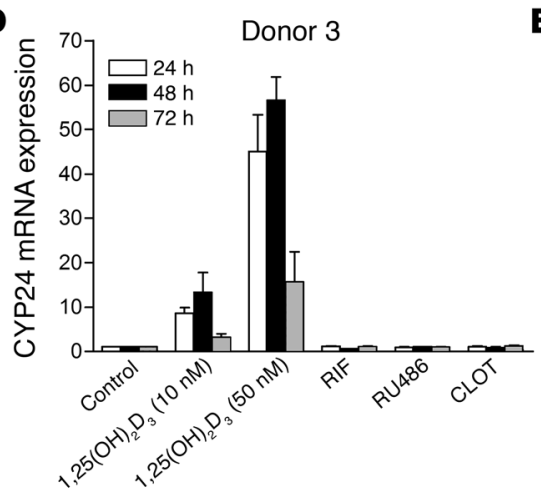

Donor 1

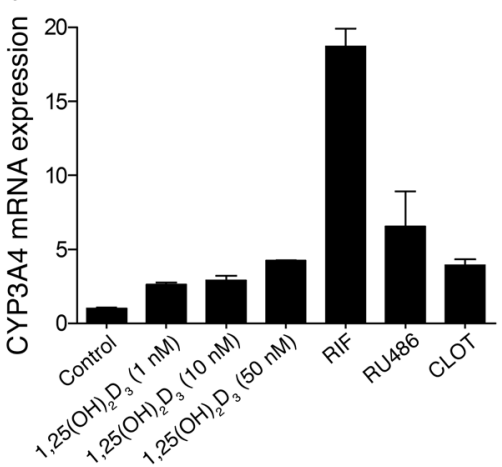

Donor 2
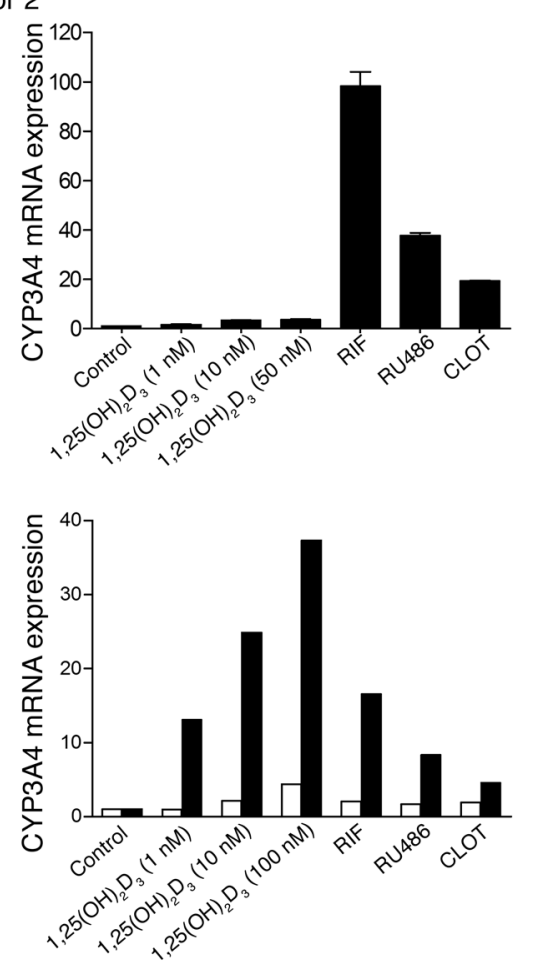

E

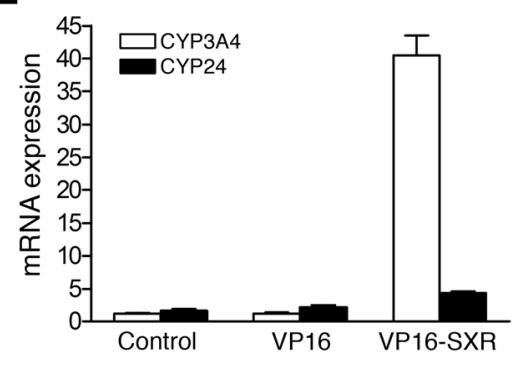

Figure 2

$1,25(\mathrm{OH})_{2} \mathrm{D}_{3}$ but not SXR ligands induce CYP24 gene expression in human primary hepatocytes and intestinal cells. (A and B) Human primary hepatocytes from 2 different donors were treated with 1,10 , or $50 \mathrm{nM}$ of the VDR ligand $1,25(\mathrm{OH})_{2} \mathrm{D}_{3}$ or $10 \mu \mathrm{M}$ of SXR ligands RIF, CLOT, or RU486 for 24 hours as indicated. Total RNA from each sample was isolated, and the expression of CYP3A4 and CYP24 genes was determined by QRT-PCR assays. (C) Two different immortalized human intestinal cell lines, Caco-2 and LS180, were treated with 1,10 , or $100 \mathrm{nM}$ of the VDR ligand $1,25(\mathrm{OH})_{2} \mathrm{D}_{3}$ or $10 \mu \mathrm{M}$ of SXR ligands RIF, CLOT, or RU486 for 24 hours as indicated. Total RNA from each sample was isolated, and the expression of CYP3A4 and CYP24 genes was determined by QRT-PCR assays. (D) Human primary hepatocytes from donor 3 were treated with 10 or $50 \mathrm{nM}$ of the VDR ligand $1,25(\mathrm{OH})_{2} \mathrm{D}_{3}$ or $10 \mu \mathrm{M}$ of SXR ligands RIF, CLOT, or RU486 for 24,48 , or 72 hours as indicated. Total RNA from each sample was isolated, and the expression of CYP24 genes was determined by QRT-PCR assays. (E) LS180 cells were transfected with control vector, VP16, or VP16-SXR expression vector; total RNA from each sample was isolated; and the expression of CYP3A4 and CYP24 genes was determined by QRT-PCR assays.

with 10 or $50 \mathrm{nM}$ of $1,25(\mathrm{OH})_{2} \mathrm{D}_{3}$ or $10 \mu \mathrm{M}$ SXR ligands for 24, 48, or 72 hours. As expected, 10


expression after 24 hours incubation. This induction reached a peak after incubation of primary hepatocytes with $1,25(\mathrm{OH})_{2} \mathrm{D}_{3}$ for 48 hours and significantly decreased after 72 hours of incubation. On the other hand, SXR ligands did not induce the CYP24 expression even after as long as 72 hours incubation (Figure 2D). The observation that SXR ligands did not induce CYP24 expression in both primary hepatocytes and immortalized intestinal cells suggested that CYP24 is not a direct target gene of SXR.

To further confirm that activation of SXR does not upregulate CYP24 expression, we transfected LS180 cells with a mutant form of SXR (VP16-SXR) that constitutively activates SXR target genes in vitro and in vivo (28). Total RNA from VP16-SXR transfected cells was isolated, and QRT-PCR was performed. Overexpression of VP16-SXR successfully induced (40-fold) the expression of the SXR target gene CYP3A4 but had only a slight effect $(<2$-fold compared with VP16) on CYP24 expression (Figure 2E). These results, and those described above, suggest that CYP24 expression is not induced to any appreciable extent by either ligand-activated SXR or expression appreciably in either intestinal cell line, in agreement with the human primary hepatocyte data. In contrast, $1,25(\mathrm{OH})_{2} \mathrm{D}_{3}$ markedly induced CYP24 expression in both Caco-2 and LS180 cells. Next, we tested whether longer exposure to SXR ligands can affect CYP24 expression. Human primary hepatocytes were treated the constitutively active VP16-SXR.

SXR does not transactivate the CYP24 promoter or bind to VDREs in the CYP24 promoter. Since activation of SXR had a minimal to undetectable effect on CYP24 expression in both hepatocytes and LS180 cells, we next tested whether SXR can directly regulate CYP24 pro- 

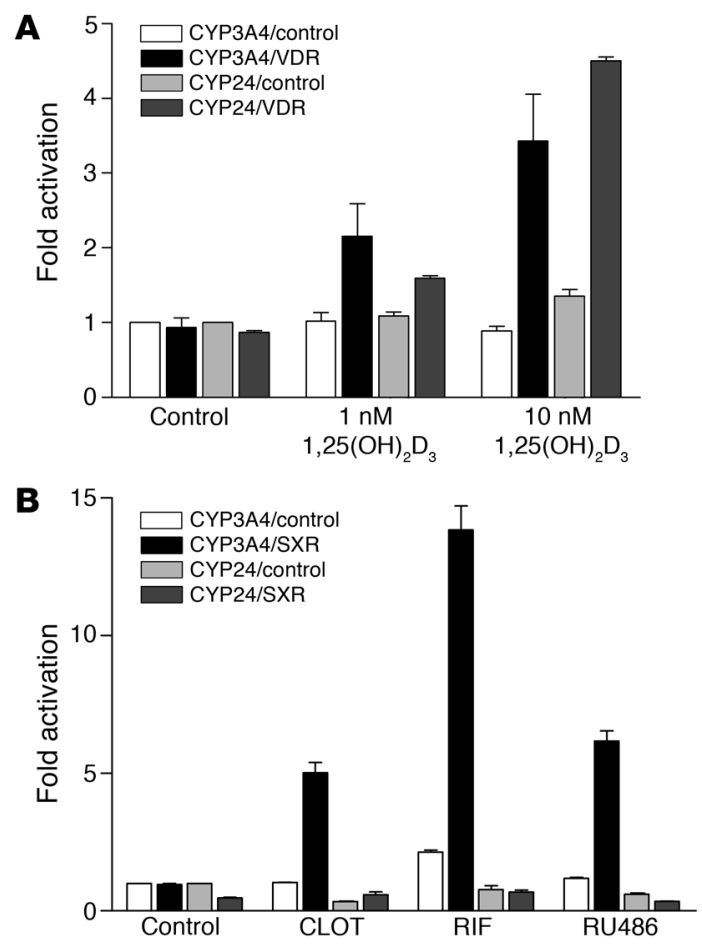

moter activity (24). HepG2 cells were transfected with a CYP24 or CYP3A4 promoter reporter, in the absence or presence of SXR or VDR expression plasmids. Cells were treated with the VDR ligand, $1,25(\mathrm{OH})_{2} \mathrm{D}_{3}$, or SXR ligands, RIF, CLOT, or RU486, at the indicated concentrations (Figure 3). Consistent with the gene expression data, SXR agonists only transactivated the CYP3A4 reporter and not the CYP24 reporter, in the presence of SXR (Figure 3B). In

\section{Figure 3}

VDR but not SXR transactivates the CYP24 promoter. (A) HepG2 cells were transiently transfected with full-length VDR together with a CYP3A4-luc reporter or CYP24-luc reporter and CMX- $\beta$-galactosidase transfection control plasmid. After transfection, cells were treated with

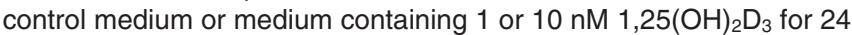
hours. (B) HepG2 cells were transiently transfected with full-length SXR together with a CYP3A4-luc reporter or CYP24-luc reporter and $\mathrm{CMX}-\beta$-galactosidase transfection control plasmid. After transfection, cells were treated with control medium or medium containing $10 \mu \mathrm{M}$ CLOT, RIF, or RU486 for 24 hours.

the presence of VDR, $1,25(\mathrm{OH})_{2} \mathrm{D}_{3}$ was able to induce both CYP24 and CYP3A4 reporter activity, which confirmed VDR's role in the regulation of both genes (Figure 3A). These results indicate that SXR does not regulate CYP24 promoter activity, which is consistent with our gene expression analysis from primary hepatocytes and intestinal cells.

The promoter of CYP24 has been well characterized, and 2 VDR binding motifs have been previously identified: VDRE-1, located -174 to -151 , and VDRE-2, located -294 to $-274(24,29)$. To further understand the failure of SXR to regulate CYP24 expression, we tested whether SXR can directly bind to those response elements by EMSA. SXR, VDR, and RXR proteins were prepared by in vitro transcription and translation. VDR-RXR heterodimers were able to bind both VDRE-1 and VDRE-2, as expected (Figure 4A). Excess cold probes decreased VDR-RXR binding to those elements, confirming the specificity of the interaction. The SXR-RXR heterodimer, on the other hand, could not bind to either of those motifs under the conditions employed (Figure 4A). In contrast, SXR-RXR was able to bind to the ER6 motif from the CYP3A4 promoter, and this was competed by addition of excess cold ER6 probe but not to any appreciable degree by excess cold VDRE-1
A


VDRE-2
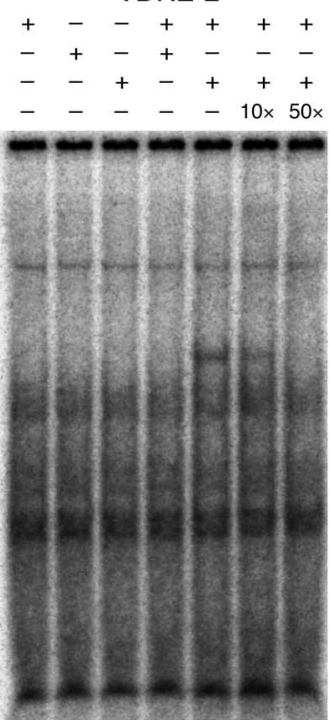

B $\mathrm{RXR}-+{ }_{-}+++++++$

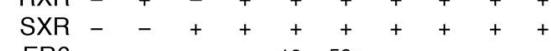

ER6 - - $-\quad-10 \times 50 \times \quad-\quad-\ldots$

VDRE-1 - _ _ _ _ $-10 \times 50 \times \quad \ldots$

VDRE-2 - $-\quad-\quad-\quad-\quad-\quad-\quad-10 \times 50 \times$

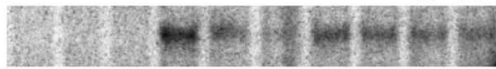

C $\mathrm{RXR}-+--+++++2 x$

SXR - - + - + - 1x 2x 4x 4x

VDR - $-\quad+\quad+\quad+\quad+\quad+\quad+\quad+$



D $\mathrm{RXR}-+-\mathrm{C}_{-}+++++2 \times$

SXR - - + - + - 1× 2x 4x 4x

VDR

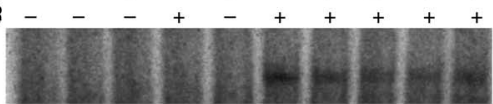

\section{Figure 4}

SXR does not bind to the VDRE-1 and VDRE-2 motifs in the CYP24 promoter region. (A) In vitro-translated VDR, SXR, and RXR, as indicated, were incubated with [ $\left.{ }^{32} \mathrm{P}\right]$-labeled VDRE-1 or VDRE-2 probe and analyzed by EMSA. Ten- or 50-fold excess of unlabeled VDRE-1 or VDRE-2 probes was used for competition experiments. (B) In vitro-translated SXR and RXR were incubated with a [32P]-labeled ER6 motif, and 10- or 50-fold excess of unlabeled ER6, VDRE-1, or VDRE-2 probes was used for competition experiments. (C and D) In vitro-translated VDR and RXR were incubated with [32P]-labeled VDRE-1 (C) or VDRE-2 (D) along with increasing amounts of SXR or RXR protein and analyzed by EMSA. 


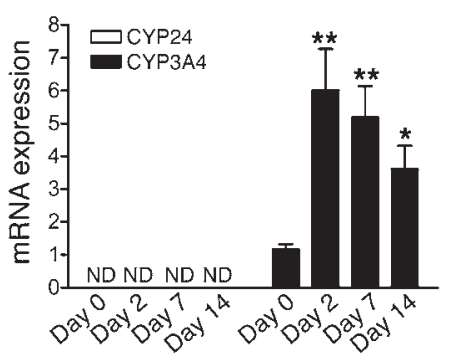

or VDRE-2 probes (Figure 4B). Coincubation of VDR-RXR protein with increasing amounts of SXR protein interfered slightly with VDR-RXR heterodimer binding to either VDRE-1 or VDRE-2 elements (Figure 4, C and D). However, this inhibition could be due to a weak nonspecific effect or competition for limited RXR protein, given that the effect of SXR did not appear to be protein concentration dependent, and an increase in the amount of RXR protein rescued this inhibitory effect. Together, these results suggest that only VDR-RXR, but not SXR-RXR, binds to the known VDR response elements in the CYP24 promoter, which explains our observation that activation of SXR does not induce CYP24 expression or transactivate its promoter in reporter gene assays.

Treatment with the SXR agonist RIF induces duodenal CYP3A4 but not CYP24 expression in healthy human volunteers. To confirm that SXR activation does not affect CYP24 expression in vivo, we analyzed duodenal epithelial biopsy samples collected from 6 healthy human volunteers before and after 2,7 , or 14 days of oral RIF administration ( $150 \mathrm{mg}$ every 6 hours) using QRT-PCR. As seen in Figure 5, CYP2 4 mRNA was undetectable in baseline biopsy samples, and this was unchanged following RIF treatment. In contrast, the SXR agonist elicited an expected marked (5-fold) induction of CYP3A4 expression after 2 days of RIF treatment. The inductive effect was slightly decreased following longer exposures to RIF but still significant even after 14 days of RIF treatment. The lack of detection of CYP24 mRNA in duodenal biopsy samples was not a methodological problem, as it was clearly detected in human kidney and at very low levels in another set of archived jejunal samples (Figure 1).

Crosstalk between $S X R$ and VDR coordinately regulates CYP24 promoter activity. Our in vitro and in

\section{Figure 6}

Crosstalk between SXR and VDR coordinately regulates CYP24 promoter activity. HepG2 cells were transiently transfected with SXR or/and VDR expression plasmids along with a CYP24-luc reporter and $\mathrm{CMX}-\beta$-galactosidase control plasmid, as indicated. (A) After transfection, cells were treated with control medium or medium containing 1,10 , or $100 \mathrm{nM} 1,25(\mathrm{OH})_{2} \mathrm{D}_{3}$ and $10 \mu \mathrm{M}$ RIF as indicated for 24 hours. (B) After transfection, cells were treated with $100 \mathrm{nM} 1,25(\mathrm{OH})_{2} \mathrm{D}_{3}$ and 1, 5, and $10 \mu \mathrm{M}$ RIF for 24 hours. (C) HepG2 cells were transfected with increasing amounts of SXR at 1:1,2:1, or $4: 1$ ratio with VDR expression vector. After transfection, cells were treated with $100 \mathrm{nM} 1,25(\mathrm{OH})_{2} \mathrm{D}_{3}$.

\section{Figure 5}

Induction of duodenal CYP3A4 but not CYP24 expression in healthy volunteers treated with RIF. The duodenal epithelial biopsy samples were collected from 6 healthy human volunteers before and after 2, 7, or 14 days of oral RIF administration (150 mg every 6 hours). Total RNA was isolated from biopsy samples, and the expression of CYP3A4 and CYP24 was analyzed by QRT-PCR. ND, not detectable. Statistically significant expressions compared with conditions before RIF administration (day 0 ) are marked with asterisks; ${ }^{*} P<0.05$ and ${ }^{* *} P<0.01$.

vivo data indicated that SXR does not transactivate the CYP24 promoter, nor does it upregulate CYP24 expression. However, we noted that CYP24 was expressed at undetectable or very low levels in the human small intestine despite the high expression levels of VDR (Figure 1) and its known physiological function in this organ. CYP24 was also essentially absent from the human liver, although VDR expression at this site was also very low. Nuclear receptors can repress transcriptional responses to diverse signaling pathways, which is an essential component of their biological activities (30). Indeed, it has been reported recently that SXR can crosstalk with constitutive androstane receptor (CAR) and suppress its effects on gene transcription (31). Accordingly, we tested whether SXR negatively affects CYP24 expression by repressing VDR activation. HepG2 cells were transiently transfected with SXR or VDR expression plasmids, or with both plasmids, along with a CYP2 4 reporter, and then treated with $1,25(\mathrm{OH})_{2} \mathrm{D}_{3}$ or the
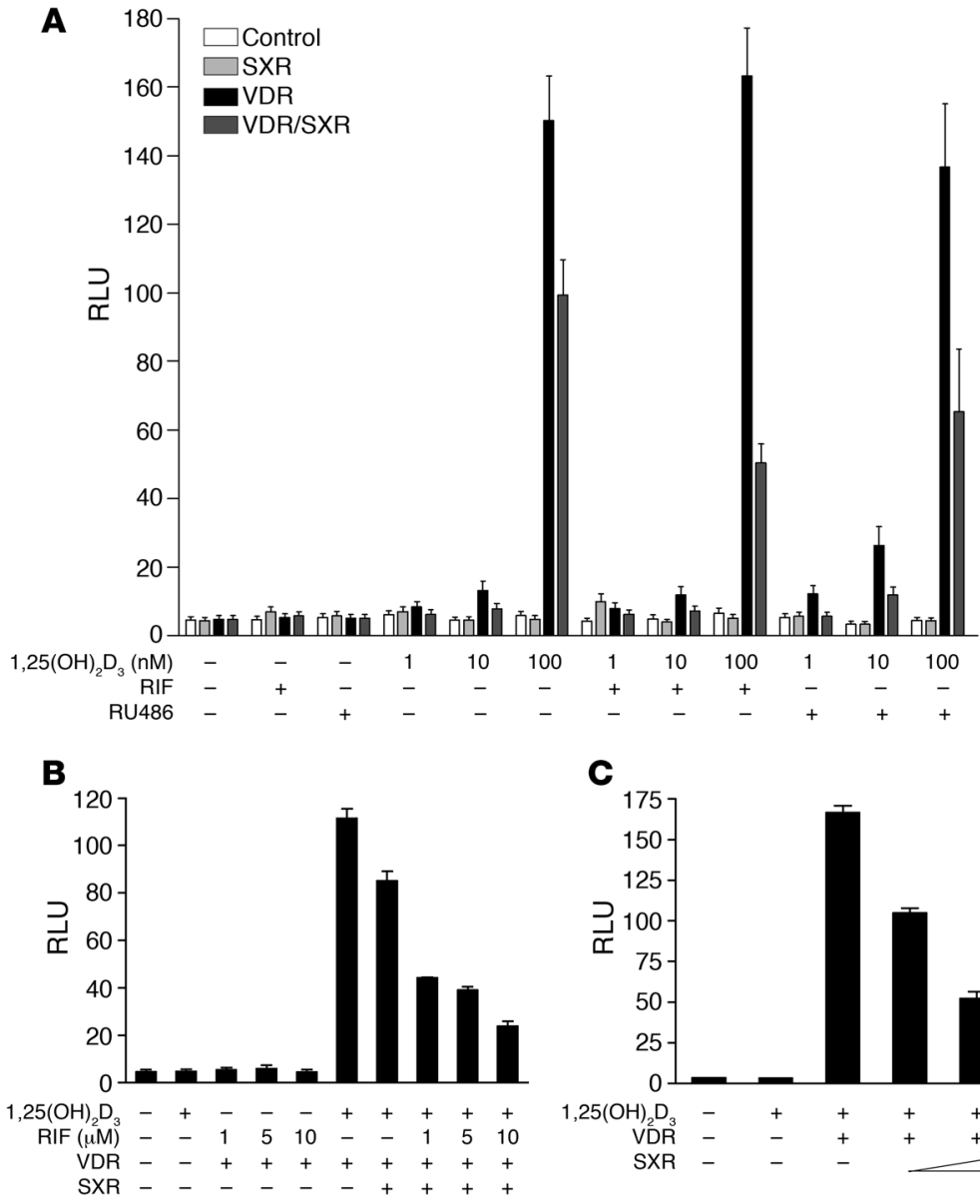

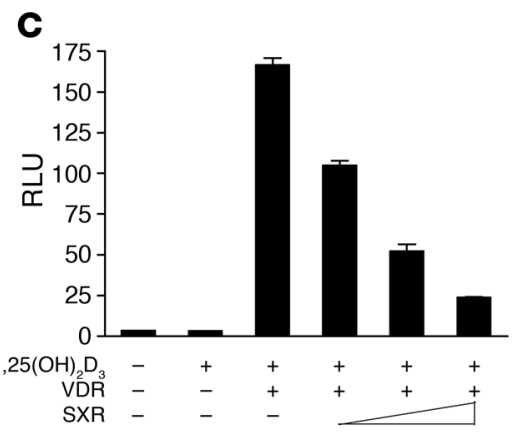



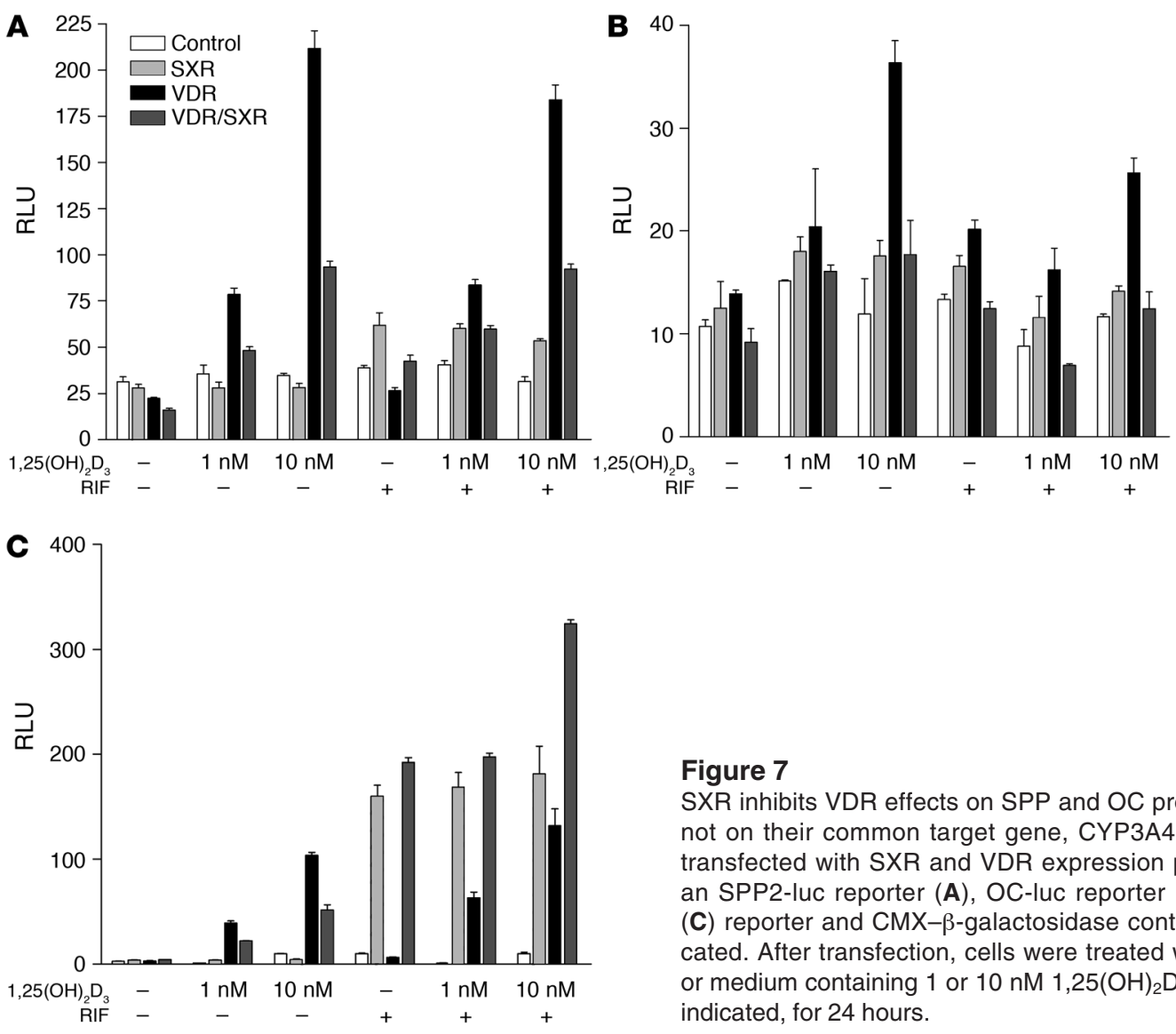

\section{Figure 7}

SXR inhibits VDR effects on SPP and OC promoter activities but not on their common target gene, CYP3A4. HepG2 cells were transfected with SXR and VDR expression plasmids along with an SPP2-luc reporter (A), OC-luc reporter (B), or CYP3A4-luc (C) reporter and $\mathrm{CMX}-\beta$-galactosidase control plasmid, as indicated. After transfection, cells were treated with control medium or medium containing 1 or $10 \mathrm{nM} 1,25(\mathrm{OH})_{2} \mathrm{D}_{3}$ and $10 \mu \mathrm{M}$ RIF, as indicated, for 24 hours.

SXR ligands RIF or RU486. As shown in Figure 6A, $1,25(\mathrm{OH})_{2} \mathrm{D}_{3}$ enhanced CYP24 reporter activity mediated by VDR was repressed when SXR was coexpressed. The addition of SXR ligands further enhanced this repressive effect. RIF and RU486 had no significant impact on CYP24 reporter activity in the absence of SXR (Figure $6 \mathrm{~A})$. Furthermore, the repression of CYP24 activity by the SXR ligand RIF was dose dependent in the presence of SXR (Figure 6B). The repression of CYP24 promoter activity was also proportional to the ratio of SXR to VDR expression vectors. When cells were transfected with increasing amounts of SXR expression vector, the ability of SXR to repress CYP24 activity was further enhanced (Figure $6 \mathrm{C}$ ). Considering the high abundance of SXR in the human small intestine (Figure 1), this negative crosstalk between SXR and VDR may explain the low levels of CYP24 expression in the intestine, despite the high levels of VDR. Similarly, SXR may repress the expression of CYP24 in the liver, although hepatic VDR expression is low and therefore unlikely to support significant gene transcription. In contrast, the low level of SXR in the kidney may permit optimal expression and function of CYP24 enzyme.

SXR inhibits VDR effects on osteopontin and osteocalcin promoter activities but not on their common target gene, CYP3A4. We next tested whether SXR is able to inhibit other VDR-mediated promoter activities in addition to those in CYP24. Reporter constructs containing the human osteopontin (SPP) or osteocalcin (OC) promoters, which contain known VDREs, and regulated by VDR (32-34) were transfected into HepG2 cells in the absence or presence of SXR or VDR expression vectors. Cells were then cultured with 1 or $10 \mathrm{nM} 1,25(\mathrm{OH})_{2} \mathrm{D}_{3}, 10 \mu \mathrm{M}$ RIF, or a mixture of both, and then reporter activities were measured. As expected, $1,25(\mathrm{OH})_{2} \mathrm{D}_{3}$ was able to induce both SPP (Figure 7A) and OC (Figure 7B) promoter activities in the presence of VDR. In the presence of SXR alone, RIF had only slight effects on SPP and OC reporter activities. Similar to CYP24 regulation, cotransfection with SXR significantly inhibited VDR-mediated SPP and OC promoter activities. The addition of RIF didn't further enhance the repressive effect of SXR.

Since SXR and VDR can both bind to and transactivate the CYP3A4 promoter, we also investigated how SXR and VDR coordinately regulate CYP3A4 promoter activity. A reporter construct containing the CYP3A4 promoter (XREM-luc) was transfected into HepG2 cells in the absence or presence of SXR or VDR expression vectors. Cells were then treated with 1 or $10 \mathrm{nM} 1,25(\mathrm{OH})_{2} \mathrm{D}_{3}$, $10 \mu \mathrm{M}$ RIF, or a mixture of both, and reporter activities were measured. In the presence of VDR, $1,25(\mathrm{OH})_{2} \mathrm{D}_{3}$ was able to transactivate the CYP3A4 promoter, while RIF also transactivated the same promoter in the presence of SXR (Figure 7C). In addition, unlike results obtained with the CYP24 promoter construct (Figure 6A), when HepG2 cells were cotransfected with both VDR and SXR, cotreatment of $1,25(\mathrm{OH})_{2} \mathrm{D}_{3}$ and RIF further enhanced CYP3A4 promoter activity (Figure $7 \mathrm{C}$ ). These data suggest that SXR represses VDR activation of some target genes, such as CYP24, OC, and SPP, but not the common target gene, CYP3A4.

Pregnenolone 16a-carbonitrile does not induce CYP24 expression in vivo, and $1,25(\mathrm{OH})_{2} \mathrm{D}_{3}$-induced CYP24 expression is enhanced in PXRknockout mice. In order to obtain additional in vivo evidence for the upregulation of CYP24 by VDR but not SXR, we treated wild-type and PXR-knockout mice with either the PXR ligand pregneno- 

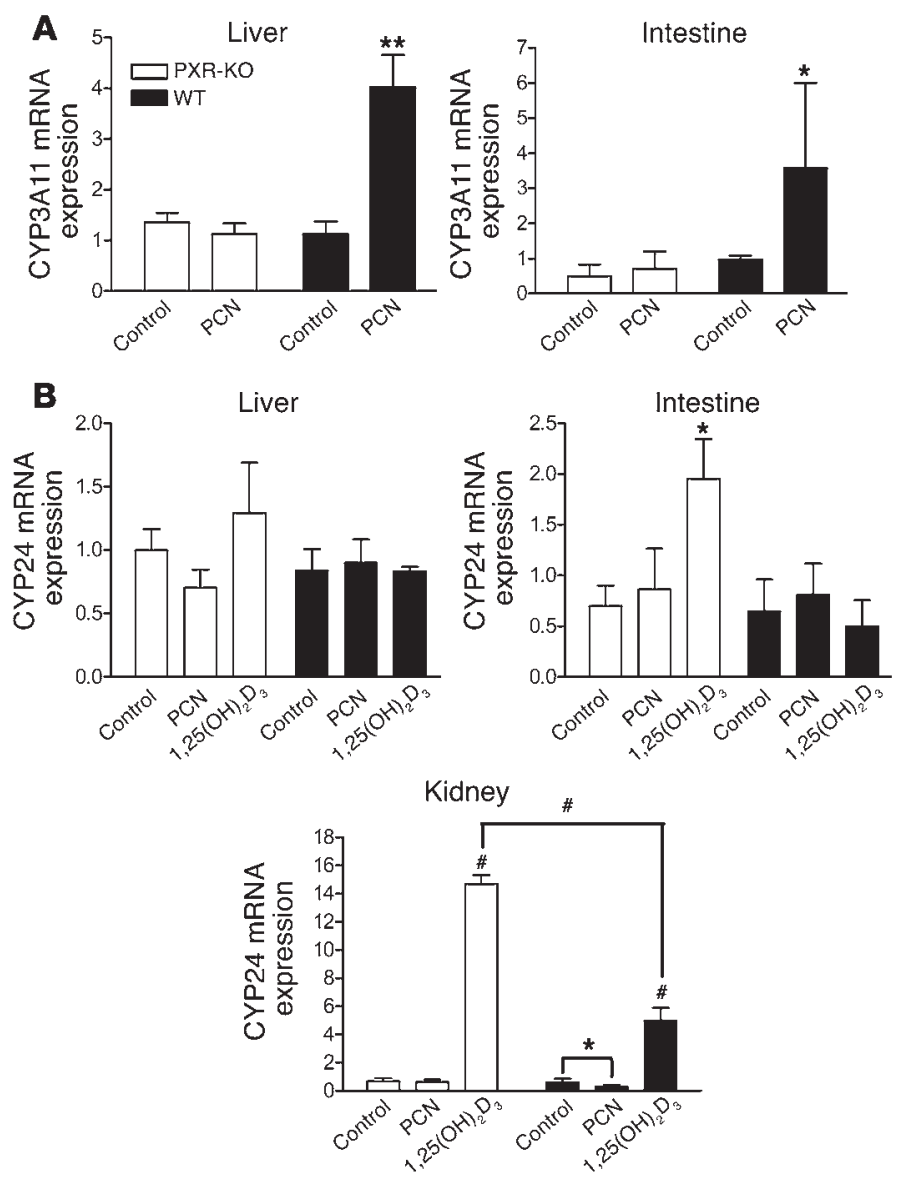

lone $16 \alpha$-carbonitrile (PCN) or the VDR ligand $1,25(\mathrm{OH})_{2} \mathrm{D}_{3}$ for 3 consecutive days and analyzed the expression levels of CYP24 and CYP3A in liver, kidney, and small intestine. As expected, PCN treatment significantly induced CYP3A11 expression in the liver and intestine of wild-type mice but not in PXR-knockout mice (Figure 8A). CYP24 mRNA was not elevated by PCN treatment in the liver, intestine, or kidney of either wild-type or PXR-knockout mice, which is consistent with our in vitro analysis demonstrating that SXR does not activate CYP24 transcription. $1,25(\mathrm{OH})_{2} \mathrm{D}_{3}$ was able to induce CYP24 expression in only the kidney (Figure 8C), but not the liver and small intestine, of wild-type mice (Figure 8B), despite the high level of VDR in the small intestine. Moreover, the inductive effect of $1,25(\mathrm{OH})_{2} \mathrm{D}_{3}$ in the kidney was markedly enhanced in PXR-knockout mice, compared with wild-type mice. In addition, $1,25(\mathrm{OH})_{2} \mathrm{D}_{3}$ treatment was also able to elicit a modest $(2.5$-fold $)$ but significant inductive effect in small intestine (but not liver) of PXR-knockout mice, consistent with the absence of repressive activity from PXR on CYP24 expression. Interestingly, PCN treatment significantly inhibited renal CYP24 expression in wild-type mice, but not in PXR-knockout animals. Taken together with the findings from our CYP24 promoter activity analysis, these results strongly suggest that PXR represses VDR-mediated CYP24 expression and that $1,25(\mathrm{OH})_{2} \mathrm{D}_{3}$-induced CYP2 4 expression is enhanced when the PXR repression is removed in PXR-knockout mice.

\section{Discussion}

VDR mediates the genomic effects of $1,25(\mathrm{OH})_{2} \mathrm{D}_{3}$ in the small intestine, kidney, and bone, organs whose integrated activities

\section{Figure 8}

Activation of mouse PXR by PCN does not induce CYP24 expression in mice, and VDR-mediated CYP24 expression is enhanced by PXR knockout. Ten-week-old male PXR-knockout and C57BL6/J (wild-type) mice (3 per group) were injected intraperitoneally with vehicle control (DMSO), PXR ligand PCN (40 mg/kg), or VDR ligand $1,25(\mathrm{OH})_{2} \mathrm{D}_{3}(50 \mathrm{ng} /$ mouse) for 3 consecutive days. Tissues were collected, and gene expression in the specific tissues was determined by QRT-PCR. (A) Expression of the PXR target gene CYP3A4 in PXR-knockout or WT mice was determined by QRTPCR. Total RNA was isolated from liver and intestine, as indicated. (B) Expression of the VDR target gene CYP24 in PXR-knockout or WT mice was determined by QRT-PCR. Total RNA was isolated from liver, intestine, and kidney, as indicated. ${ }^{\star} P<0.05$, ${ }^{\star *} P<0.01$, and $\# P<0.001$.

function to regulate calcium and phosphorus homeostasis (35). $1,25(\mathrm{OH})_{2} \mathrm{D}_{3}$ also regulates CYP24, which is a key enzyme in $1,25(\mathrm{OH})_{2} \mathrm{D}_{3}$ catabolism. Enhanced CYP24 synthesis by $1,25(\mathrm{OH})_{2} \mathrm{D}_{3}$ provides negative-feedback control of hormonal effects in target tissues through the formation of inactive metabolite(s) (3). Induction of $1,25(\mathrm{OH})_{2} \mathrm{D}_{3}$ catabolism is thought to contribute to osteomalacia that can occur in patients treated long term with some antiepileptic drugs such as phenytoin, carbamazepine, and phenobarbital (11), which are ligands for SXR. Pascussi et al. attributed this adverse effect to an induction of CYP24 mediated by SXR activation (24). They reported that SXR/PXR is able to bind to the CYP24 promoter and induce CYP24 gene expression in primary hepatocytes and kidney, which would enhance $1,25(\mathrm{OH})_{2} \mathrm{D}_{3}$ degradation and subsequently diminish its biological effects in the body (24). However, based on substantial evidence from in vitro and in vivo experimental models, we conclude that SXR does not transactivate the CYP24 promoter, nor does it induce CYP24 expression to any appreciable extent. Instead, SXR inhibited VDR-mediated CYP24 promoter activity, and CYP24 expression was low or nondetectable in those tissues containing high levels of SXR, including the small intestine, which has a high level of VDR expression. Moreover, these repressive effects were enhanced by SXR ligand activation, and $1,25(\mathrm{OH})_{2} \mathrm{D}_{3}$-induced CYP24 expression in the kidney and small intestine was enhanced in PXR-knockout mice. This renal effect is quite remarkable, given that basal expression of PXR in the kidney is relatively low compared with that in intestine or liver, but presumably still sufficient to elicit a repressive effect in the wild-type animals. Finally, the inability of SXR/PXR to activate CYP24 is strongly supported by our data from healthy humans showing that RIF treatment did not induce duodenal CYP24 expression, despite profound induction of CYP3A4 in the same tissue.

We acknowledge that there are key differences between some of our experimental results and those reported by Pascussi et al., including the absence of an inductive effect by RIF on CYP24 expression in cultured human hepatocytes (24). Pascussi et al. reported a 20-fold increase in CYP24 mRNA in cells culture with $10 \mu \mathrm{M}$ RIF for 48 hours and a time-dependent increase in CYP24 mRNA following treatment with $20 \mu \mathrm{M}$ RIF. We saw no induction by $10 \mu \mathrm{M}$ RIF or the other SXR agonists tested after 24,48 , or 72 hours of treatment (Figure 2D). The difference in experimental outcome could not be explained by assay sensitivity, as we found that CYP24 in human hepatocytes was readily induced many fold 
by $1,25(\mathrm{OH})_{2} \mathrm{D}_{3}$ in a dose- and time-dependent manner. We also note a discrepancy in the effect of PCN on the renal expression of CYP24 in wild-type mice. Pascussi et al. reported a 2.2-fold increase in renal CYP24 mRNA content, whereas we observed a significant reduction in gene expression (Figure $8 \mathrm{~B}$ ). Again we are at a loss to explain the difference other than to note that we employed a slightly lower dose of PCN (40 mg/ $\mathrm{kg}$ versus $100 \mathrm{mg} / \mathrm{kg}$ ) and treated animals for fewer days (3 versus 6 days). However, we did observe a 5 -fold induction of renal CYP2 4 in animals treated with $1,25(\mathrm{OH})_{2} \mathrm{D}_{3}$, indicating adequate assay sensitivity to detect a PCN effect. Finally, we were unable to show by EMSA that SXR binds to the CYP24 VDRE-1 and VDRE-2 motifs (Figure 4A), in contrast to clear evidence reported by Pascussi et al. of SXR and SXR-RXR binding to the same elements. It is possible that methodological differences account for the discrepant outcomes, although in vitro-synthesized receptor proteins and identical VDRE oligonucleotides were employed by both laboratories.

We recently reported that CYP3A4, and not CYP24, played the dominant role in 23- and 24-hydroxylation of $1,25(\mathrm{OH})_{2} \mathrm{D}_{3}$ under constitutive and induced conditions in human small intestine and liver (8). Data from this report suggests that SXR negatively regulates CYP24 expression in the small intestine, liver, and even kidney under constitutive conditions and yet mediates enhanced $1,25(\mathrm{OH})_{2} \mathrm{D}_{3}$ catabolism through induction of CYP3A4 in liver and small intestine in response to treatment with SXR ligands such as those associated with drug-induced osteomalacia. Indeed, results from the healthy volunteer study clearly show no increase in duodenal CYP24 following RIF treatment and instead the expected marked increase in CYP3A4 expression. Admittedly, we cannot exclude the possibility that RIF elicited a transient increase in intestinal CYP24 expression during the 6-hour dose interval, similar to that seen in rats treated acutely with $1,25(\mathrm{OH})_{2} \mathrm{D}_{3}$ (36-38), but the effect would have to have been short lived and discordant with the effect of the SXR agonist on CYP3A4 expression. Overall, our data strongly suggest that any change in intestinal (or hepatic) $1,25(\mathrm{OH})_{2} \mathrm{D}_{3}$ metabolism following chronic treatment with SXR agonists such as phenytoin and RIF would be more likely explained by an induction of CYP3A4 than CYP24.

The regulation of bone mass in mammals is a complex process that requires a balance between the bone-forming cells (osteoblasts) and bone-resorbing cells (osteoclasts) (39). In our previous report, we found that vitamin $\mathrm{K}_{2}$, a molecule used clinically to prevent and treat osteoporosis, is able to bind to and activate SXR and is thus a bona fide SXR ligand (40). Vitamin $\mathrm{K}_{2}$ treatment of osteosarcoma cells increased mRNA levels for the osteoblast markers bone alkaline phosphatase, osteoprotegerin, SPP, and matrix Gla protein. The known SXR activators RIF and hyperforin induced, rather than inhibited, this panel of bone markers to a similar extent as did vitamin $\mathrm{K}_{2}$. Vitamin $\mathrm{K}_{2}$ is able to induce bone markers in primary osteoblasts isolated from wild-type murine calvaria but not in cells isolated from mice deficient in the SXR ortholog PXR. Combined with our results showing that SXR inhibited CYP24 expression and that CYP3A4 plays the dominant role in $1,25(\mathrm{OH})_{2} \mathrm{D}_{3}$ hydroxylation in human small intestine and liver, this indicates that SXR may have dual but opposing roles in mediating bone homeostasis. On one hand, activation SXR of by some drugs induces CYP3A4 expression in liver and intestine, which promotes metabolism of $1,25(\mathrm{OH})_{2} \mathrm{D}_{3}$ and may contribute to impaired calcium absorption. On the other hand, vitamin $\mathrm{K}_{2}$ and these same SXR ligands can induce osteoblastic bone markers in bones and inhibit $1,25(\mathrm{OH})_{2} \mathrm{D}_{3}$-mediated CYP24 expression in kidney, which may induce bone cell formation and enhance systemic levels of $1,25(\mathrm{OH})_{2} \mathrm{D}_{3}$, eventually opposing the development of osteoporosis. Therefore, the effects of SXR on bone homeostasis are tissue specific and signal specific, and drug-induced osteomalacia may be far more complicated than just a phenomenon of enhanced CYP3A4 (or CYP24) expression and induced $1,25(\mathrm{OH})_{2} \mathrm{D}_{3}$ catabolism. Perhaps the development of osteomalacia and osteoporosis, which is not seen in all patients receiving CYP3A4 inducers, occurs because of impaired osteoblast activation in response to SXR agonists. Thus, drug-induced osteomalacia may be due, at least in part, to factors other than altered vitamin D metabolism.

Nuclear receptors can repress transcriptional responses to diverse signaling pathways, which can be an essential component of their full spectrum of biological activities (30). It was reported recently that SXR can also negatively regulate other signaling pathways. SXR represses CAR-mediated gene activation involved in bilirubin detoxification and that CAR target genes are upregulated in PXRknockout mice (31). In addition, we also found that SXR represses the NF- $\kappa \mathrm{B}$ signaling pathway and may contribute to the immunosuppressive effects of some drugs (C. Zhou and B. Blumberg, unpublished observations). The present study revealed that SXR also represses VDR-mediated CYP24 gene activation. This effect was SXR dependent, and its ligands further enhanced the downregulation of CYP24 transcription (Figure 6). Not surprisingly, SXR-mediated gene repression is selective in that SXR negatively affects CYP24 transcription but not CYP3A4. Although transrepression by nuclear receptors and crosstalk between nuclear receptors and other signaling pathways have been studied extensively, the molecular mechanisms are still far from completely understood (41). SXR-mediated repression of CYP24 cannot be explained by competitive DNA binding, as, in our hands, SXR did not bind to the VDR motifs in the CYP24 promoter and VDR-RXR binding to those motifs was not affected appreciably by addition of SXR. Since both SXR and VDR recruit same coactivators, such as SRC-1, PBP, and p300/CBP $(42,43)$, ligand-independent and ligand-dependent coactivator recruitment by SXR may at least in part account for the inhibition of VDR activities. SXR is also able to interact with corepressors, SMRT and $\operatorname{NCoR}(27,42)$, which may also be involved in transrepression of VDR activities by SXR. It also remains to be determined whether activation of SXR blocks the nuclear translocation of VDR and therefore inhibit its genomic activities.

In conclusion, crosstalk between SXR and VDR regulates CYP24 expression and $1,25(\mathrm{OH})_{2} \mathrm{D}_{3}$ catabolism. CYP24 expression is suppressed at sites of high SXR expression, and CYP3A4 mediates $1,25(\mathrm{OH})_{2} \mathrm{D}_{3}$ hydroxylation reactions. SXR activation of CYP3A4 and not CYP24 is likely to be responsible for enhanced catabolism of $1,25(\mathrm{OH})_{2} \mathrm{D}_{3}$ that is associated with long-term treatment with SXR ligands. Although its bone and intestinal effects may be paradoxical, SXR appears to be an important factor in vitamin D and bone homeostasis, in addition to xenobiotic homeostasis and cholesterol and bile acid detoxification. The current study widens the pharmacological implications of SXR action beyond xenobiotic response and establishes SXR as a potential therapeutic target for clinical treatment or prevention of osteomalacia and osteoporosis.

\section{Methods}

Reagents and plasmids. RIF, RU486, and CLOT were purchased from SigmaAldrich. $1,25(\mathrm{OH})_{2} \mathrm{D}_{3}$ was purchased from Calbiochem, and PCN was purchased from BioMol International. SXR, VDR, VP16-SXR, CMX- $\beta$-gal 
expression vectors; SXR-dependent CYP3A4 promoter reporter (CYP3A4XREM-luc); and human SPP promoter reporter (SPP-luc) have been previously described $(16,27,34,44)$. Human CYP24 promoter reporter (CYP24luc) and OC promoter reporter (OC-luc) were kindly provided by J.W. Pike (University of Wisconsin-Madison, Madison, Wisconsin, USA) (33).

Cell culture. The human hepatic cell line, HepG2, and intestinal epithelial cell lines, LS180 and Caco-2, were obtained from ATCC and cultured in DMEM containing $10 \% \mathrm{FBS}$ at $37^{\circ} \mathrm{C}$ in $5 \% \mathrm{CO}_{2}$. The cells were seeded into 6-well plates and grown in DMEM-10\% FBS until 70-80\% confluence. Twenty-four hours before treatment, the medium was replaced with DMEM containing $10 \%$ resin-charcoal-stripped FBS. Immediately before treatment, the medium was removed; the cells were washed once with PBS and then treated with compounds or DMSO vehicle for appropriate times. Human primary hepatocytes were obtained from the Liver Tissue Procurement and Distribution System (Pittsburgh, Pennsylvania, USA) as attached cells in 6-well plates. The hepatocytes were maintained in hepatocyte medium (Sigma-Aldrich) for at least 24 hours before treatment.

Transient transfection and luciferase assay. Transfection and luciferase and $\beta$-galactosidase assays were performed as described previously (27). To test the ability of SXR and VDR to activate different reporters, HepG2 cells were seeded into 12-well plates overnight and transiently transfected with the SXR or/and VDR expression plasmid, together with the CYP3A4XREMluc or CYP24-luc reporter and CMX- $\beta$-galactosidase transfection control plasmids using FuGENE 6 (Roche Applied Science) in serum-free DMEM. Twenty-four hours after transfection, the cells were treated with DMSO or EtOH as a negative control, the known SXR ligands RIF, RU486, and CLOT, $1,25(\mathrm{OH})_{2} \mathrm{D}_{3}$, or the mixture of $1,25(\mathrm{OH})_{2} \mathrm{D}_{3}$ and SXR ligands for 24 hours. The cells were lysed 24 hours after treatment, and $\beta$-galactosidase and luciferase assays were performed as described previously (45). Reporter gene activity was normalized to the $\beta$-galactosidase transfection controls and the results expressed as normalized RLU per OD $\beta$-galactosidase per minute to facilitate comparisons between plates. Fold induction was calculated relative to solvent controls. Each data point represents the mean \pm SEM of triplicate experiments that were replicated independently.

Human tissue samples. Human liver and intestine (jejunum) samples were obtained from the University of Washington School of Pharmacy Human Tissue Bank. The collection and use of these tissues for research was approved by the University of Washington Human Subjects Review Board. Human kidney RNA samples were obtained from BD Biosciences - Clontech. Total RNA was isolated from those samples and used for QRT-PCR analysis.

Animals and treatments. The following protocol was approved by the Animal Care Committee at St. Jude Children's Research Hospital. PXRknockout and C57BL6/J (wild-type) mice were maintained on standard chow. Ten-week-old male C57BL6/J and PXR-knockout mice received an intraperitoneal injection of DMSO control, PXR ligand PCN (40 mg/kg), or $1,25(\mathrm{OH})_{2} \mathrm{D}_{3}(50 \mathrm{ng} /$ mouse) for 3 consecutive days. Mice were then euthanized, and tissues were harvested for further analysis.

RNA isolation and QRT-PCR analysis. Total RNA was isolated from primary hepatocytes, LS180 cells, Caco-2 cells, and mouse and human tissues using TRIzol regent (Invitrogen Corp.) according to the manufacturer-supplied protocol. QRT-PCR was performed using gene-specific primers and the SYBR green PCR kit (Applied Biosystems) in an ABI 7900 system (Applied Biosystems). All samples were quantified using the comparative Ct method for relative quantification of gene expression, normalized to $\operatorname{GAPDH}(27,46)$. The following primer sets were used in this study: CYP3A4 (5'-GGCTTCATCCAATGGACTGCATAAAT- $3^{\prime}$ and $5^{\prime}$-TCCCAAGTATAACACTCTACACAGACAA-3'); CYP24 (5'-GGTGACATCTACGGCGTACAC-3' and 5'-CTTGAGACCCCCTTTCCAGAG-3'); VDR (5'-GACATCGGCATGATGAAGGAG-3' and $5^{\prime}$-GCGTCCAGCAGTATGGCAA-3'); SXR (5'-TGGGTGACACCTCCGAGA-3' and $5^{\prime}$-TAGGGAGACAGGCCAGCA-3'); GAPDH
(5'-GGCCTCCAAGGAGTAAGACC-3' and 5'-AGGGGAGATTCAGTGTGGTG-3'); mouse CYP3A11 (5'-CAGCTTGGTGCTCCTCTACC-3' and 5'-TCAAACAACCCCCATGTTTT-3'); mouse CYP24 (5'-CTGCCCCATTGACAAAAGGC- $3^{\prime}$ and $5^{\prime}$-CTAACCGTCGGTCATCAGC- ${ }^{\prime}$ ); mouse VDR (5'-ACCCTGGTGACTTTGACCG- ${ }^{\prime}$ and $5^{\prime}$-GGCAATCTCCATTGAAGGGG-3'); mouse PXR (5'-GACGCTCAGATCCAAACCTT-3' and 5'-TGGTCCTCAATAGGCAGGTC-3'); mouse GAPDH (5'-AACTTTGGCATTGTGGAAGG-3' and 5'-GGATGCAGGGATGATGTTCT-3').

EMSA. Two VDRE probes and 1 ER6 probe were created by annealing the oligonucleotides 5'-CCGGACGCCCTCGCTCACCTCGCTGA-3' (VDRE-1), 5'-CGAAGCACACCCGGTGAACTCCGG-3' (VDRE-2), or 5'-ATATGAACTCAAAGGAGGTCAGTG-3' (ER6) to the complementary strand. Double-stranded oligonucleotides were end labeled using T4 polynucleotide kinase (Invitrogen Corp.) and $\gamma$-[32P]-ATP (PerkinElmer). One microliter of in vitro-translated SXR, VDR, or RXR protein was incubated with $2 \mu \mathrm{g}$ poly d(I-C) (Promega), $2 \mu \mathrm{l}$ bandshift buffer $\left(50 \mathrm{mM} \mathrm{MgCl}_{2}\right.$, $340 \mathrm{mM} \mathrm{KCl})$, and $6 \mu \mathrm{l}$ delta buffer $(0.1 \mathrm{mM}$ EDTA, $40 \mathrm{mM} \mathrm{KCl}, 25 \mathrm{mM}$ HEPES [pH 7.6], 8\% Ficoll 400, $1 \mathrm{mM}$ dithiothreitol) on ice for $10 \mathrm{~min}$ utes. [32P]-labeled double-stranded oligonucleotide probe $(100,000 \mathrm{cpm})$ was then added, and the reaction was incubated for another 20 minutes on ice (27). The binding complexes were subjected to electrophoresis in a $6 \%$ nondenaturing polyacrylamide gel containing $0.5 \times$ tris-borate-EDTA (TBE). The gels were dried, and the complexes were visualized on a Phosphorimager (Amersham Biosciences).

Treatment of healthy volunteers with RIF. Six healthy adult (human) volunteers were admitted to the UNC General Clinical Research Center and placed on a whole food diet devoid of caffeine, cruciferous vegetables, and grapefruit juice. They were not smokers, and each was asked to refrain from consumption of alcohol, herbal products, dietary supplements, grapefruit products, vitamin and mineral supplements, caffeine, carbonated beverages, and medications (both over-the-counter and prescription) for the 2 weeks prior to admission. On the morning after admission and before breakfast, each subject underwent a standard upper gastrointestinal endoscopic procedure. A fiberoptic endoscope was passed through the mouth to the third portion of the duodenum (distal to the ampulla of vater), and "pinch" mucosal biopsy samples were obtained under direct vision. Upon recovery from the procedure, the subjects began treatment with oral RIF (Rifadin capsules [sanofi-aventis], $150 \mathrm{mg}$ every 6 hours) for 14 consecutive days. The endoscopic procedure with biopsies was repeated on the morning of day 3 at the end of the 6-hour dosing interval (after 2 days of RIF treatment), and again after 7 and 14 days of treatment. A standard preparation regimen was employed for each endoscopic procedure that consisted of gargling, but not swallowing, Cetacaine (14\% benzocaine, $2 \%$ butyl aminobenzoate, $2 \%$ tetracaine hydrochloride) and intravenous midazolam and meperidine as needed for sedation. Four-pinch biopsy samples obtained at each procedure were immediately placed in $500 \mu \mathrm{l}$ denaturing solution (4 M guanidine isothiocyanate, $0.5 \% \mathrm{~N}$-lauroylsarcosine, $25 \mathrm{mM}$ sodium citrate, and 0.7\% 2-mercaptoethanol, $\mathrm{pH} 7.0$ ), blended in a glass Dounce homogenizer and snap-frozen in liquid nitrogen. Total RNA was extracted using TRIzol reagent (Invitrogen Corp.). QRT-PCR was performed using gene-specific primers for CYP3A4 (5'-CCAAGCTATGCTCTTCACCG-3' and $5^{\prime}$-TCAGGCTCCACTTACGGTGC-3'), CYP24 (5'-AGCACGTTTGGGAGGATGATG-3' and $5^{\prime}$-GCACTAGGCTGCTGAGAATAC-3'), and villin (5'-CATGAGCCATGCGCTGAAC- ${ }^{\prime}$ and $5^{\prime}$-TCATTCTGCACCTCCACCTGT- $3^{\prime}$ ).Values were normalized to villin levels. Relative mRNA levels were evaluated using the $2^{-\Delta \Delta C t}$ method (46).

Statistics. Differences between 2 groups were analyzed using 2-tailed Student's $t$ test or 1-way ANOVA test. A $P$ value less than 0.05 was considered to be significant. All data are presented in the text and figures as the mean \pm SEM. 


\section{Acknowledgments}

We thank E. Poulton for technical support; Y. Xu for human tissue sample preparation; and J.W. Pike for providing plasmids. This work was supported in part by grants from the NIH to K.E. Thummel (GM63666, GM32165, and ES07033), E.G. Schuetz (GM60346), P.B. Watkins (GM38149 and RR000046), and B. Blumberg (GM60572) and a gift from Eisai Co. Ltd. to B. Blumberg. Human hepatocytes were obtained through the Liver Tissue Procurement and Distribution System (Pittsburgh, Pennsylvania, USA) funded by NIH contract N01-DK-9-2310. C. Zhou is supported by a University of
Washington School of Pharmacy Drug Metabolism, Transporter and Pharmacogenomics (DMTPR) Postdoctoral Fellowship.

Received for publication December 28, 2005, and accepted in revised form March 7, 2006.

Address correspondence to: Kenneth E. Thummel, Department of Pharmaceutics, Box 357610, University of Washington, Seattle, Washington 98195-7610, USA. Phone: (206) 543-0819; Fax: (206) 543-3204; E-mail: thummel@u.washington.edu.
1. Pike, J.W., and Shevde, N.K. 2005. The vitamin D receptor. In Vitamin D. 2nd edition. D. Feldman, F.H. Glorieux, and J.W. Pike, editors. Elsevier Academic Press. Boston, Massachusetts, USA. 167-191.

2. Jones, G., Strugnell, S.A., and DeLuca, H.F. 1998. Current understanding of the molecular actions of vitamin D. Physiol. Rev. 78:1193-1231.

3. Sutton, A.L., and MacDonald, P.N. 2003. Vitamin D: more than a "bone-a-fide" hormone. Mol. Endocrinol. 17:777-791.

4. Nagpal, S., Na, S., and Rathnachalam, R. 2005. Noncalcemic actions of vitamin $\mathrm{D}$ receptor ligands. Endocr. Rev. 26:662-687.

5. Dusso, A.S., Brown, A.J., and Slatopolsky, E. 2005. Vitamin D. Am. J. Physiol. Renal Physiol. 289:F8-F28.

6. Bouillon, R., Okamura, W.H., and Norman, A.W. 1995. Structure-function relationships in the vitamin D endocrine system. Endocr. Rev. 16:200-257.

7. Inouye, K., and Sakaki, T. 2001. Enzymatic studies on the key enzymes of vitamin D metabolism; 1 alpha-hydroxylase (CYP27B1) and 24-hydroxylase (CYP24). Biotechnol. Annu. Rev. 7:179-194.

8. Xu, Y., et al. 2006. Intestinal and hepatic CYP3A4 catalyze hydroxylation of 1alpha,25-dihydroxyvitamin $\mathrm{D}(3)$ : implications for drug-induced osteomalacia. Mol. Pharmacol. 69:56-65.

9. Zierold, C., Mings, J.A., and DeLuca, H.F. 2003. Regulation of 25-hydroxyvitamin D3-24-hydroxylase mRNA by 1,25-dihydroxyvitamin D3 and parathyroid hormone. J. Cell Biochem. 88:234-237.

10. Takeyama, K., et al. 1997. 25-Hydroxyvitamin D3 1alpha-hydroxylase and vitamin D synthesis. Science. 277:1827-1830.

11. Pack, A.M., and Morrell, M.J. 2004. Epilepsy and bone health in adults. Epilepsy Behav. 5(Suppl. 2):S24-S29.

12. Andress, D.L., et al. 2002. Antiepileptic druginduced bone loss in young male patients who have seizures. Arch. Neurol. 59:781-786.

13. Burt, R., Freston, J.W., and Tolman, K.G. 1976. The influence of phenobarbital on biotransformation of 25-hydroxycholecalciferol. J. Clin. Pharmacol. 16:393-398.

14. Shah, S.C., Sharma, R.K., Hemangini, and Chitle, A.R. 1981. Rifampicin induced osteomalacia. Tubercle. 62:207-209.

15. Karaaslan, Y., Haznedaroglu, S., and Ozturk, M. 2000. Osteomalacia associated with carbamazepine/valproate. Ann. Pharmacother. 34:264-265.

16. Blumberg, B., et al. 1998. SXR, a novel steroid and xenobiotic-sensing nuclear receptor. Genes Dev. 12:3195-3205.

17. Kliewer, S.A., et al. 1998. An orphan nuclear receptor activated by pregnanes defines a novel steroid signaling pathway. Cell. 92:73-82.

18. Lehmann, J.M., et al. 1998. The human orphan nuclear receptor PXR is activated by compounds that regulate CYP3A4 gene expression and cause drug interactions. J. Clin. Invest. 102:1016-1023.

19. Kliewer, S.A., Goodwin, B., and Willson, T.M. 2002 The nuclear pregnane $\mathrm{X}$ receptor: a key regulator of xenobiotic metabolism. Endocr. Rev. 23:687-702.

20. Xie, W., and Evans, R.M. 2002. Pharmaceutical use of mouse models humanized for the xenobiotic receptor. Drug Discov. Today. 7:509-515.

21. Willson, T.M., and Kliewer, S.A. 2002. PXR, CAR and drug metabolism. Nat. Rev. Drug Discov. 1:259-266.

22. Miki, Y., Suzuki, T., Tazawa, C., Blumberg, B., and Sasano, H. 2005. Steroid and xenobiotic receptor (SXR), cytochrome P450 3A4 and multidrug resistance gene 1 in human adult and fetal tissues. $\mathrm{Mol}$. Cell. Endocrinol. 231:75-85.

23. Dotzlaw, H., Leygue, E., Watson, P., and Murphy, L.C. 1999. The human orphan receptor PXR messenger RNA is expressed in both normal and neoplastic breast tissue. Clin. Cancer Res. 5:2103-2107.

24. Pascussi, J.M., et al. 2005. Possible involvement of pregnane X receptor-enhanced CYP24 expression in drug-induced osteomalacia. J. Clin. Invest. 115:177-186. doi:10.1172/JCI200521867.

25. Thummel, K.E., et al. 2001. Transcriptional control of intestinal cytochrome P-4503A by 1alpha,25-dihydroxy vitamin D3. Mol. Pharmacol. 60:1399-1406.

26. Drocourt, L., Ourlin, J.C., Pascussi, J.M., Maurel, P., and Vilarem, M.J. 2002. Expression of CYP3A4, CYP2B6, and CYP2C9 is regulated by the vitamin $D$ receptor pathway in primary human hepatocytes. J. Biol. Chem. 277:25125-25132.

27. Zhou, C., Tabb, M.M., Sadatrafiei, A., Grun, F., and Blumberg, B. 2004. Tocotrienols activate the steroid and xenobiotic receptor, SXR, and selectively regulate expression of its target genes. Drug Metab. Dispos. 32:1075-1082.

28. Xie, W., et al. 2000. Humanized xenobiotic response in mice expressing nuclear receptor SXR. Nature. 406:435-439.

29. Kerry, D.M., et al. 1996. Transcriptional synergism between vitamin $\mathrm{D}$-responsive elements in the rat 25-hydroxyvitamin D3 24-hydroxylase (CYP24) promoter. J. Biol. Chem. 271:29715-29721.

30. Ogawa, S., et al. 2005. Molecular determinants of crosstalk between nuclear receptors and toll-like receptors. Cell. 122:707-721.

31. Saini, S.P., et al. 2005. Dual role of orphan nuclear receptor pregnane $\mathrm{X}$ receptor in bilirubin detoxification in mice. Hepatology. 41:497-505.

32. Shaffer, P.L., and Gewirth, D.T. 2002. Structural basis of VDR-DNA interactions on direct repeat response elements. EMBOJ. 21:2242-2252.

33. Yamamoto, H., et al. 2003. 2-Methylene-19-nor(20S)-1,25-dihydroxyvitamin D3 potently stimulates gene-specific DNA binding of the vitamin D receptor in osteoblasts. J. Biol. Chem. 278:31756-31765.
34. Umesono, K., Murakami, K.K., Thompson, C.C., and Evans, R.M. 1991. Direct repeats as selective response elements for the thyroid hormone, retinoic acid, and vitamin D3 receptors. Cell. 65:1255-1266.

35. Kim, S., Shevde, N.K., and Pike, J.W. 2005. 1,25Dihydroxyvitamin D3 stimulates cyclic vitamin D receptor/retinoid X receptor DNA-binding, co-activator recruitment, and histone acetylation in intact osteoblasts. J. Bone Miner. Res. 20:305-317.

36. Lemay, J., Demers, C., Hendy, G.N., Delvin, E.E., and Gascon-Barre, M. 1995. Expression of the 1,25-dihydroxyvitamin D3-24-hydroxylase gene in rat intestine: response to calcium, vitamin D3 and calcitriol administration in vivo. J. Bone Miner. Res. 10:1148-1157.

37. Furuichi, T., Kawata, S., Asoh, Y., Kumaki, K., and Ohyama, Y. 1998. Differential time course of induction of 1alpha,25-dihydroxyvitamin D3-24hydroxylase mRNA expression in rats by 1alpha,25dihydroxyvitamin D3 and its analogs. Life Sci. 62:453-459.

38. Demers, C., Lemay, J., Hendy, G.N., and GasconBarre, M. 1997. Comparative in vivo expression of the calcitriol-24-hydroxylase gene in kidney and intestine. J. Mol. Endocrinol. 18:37-48.

39. Rodan, G.A. 1998. Bone homeostasis. Proc. Natl. Acad. Sci. U. S. A. 95:13361-13362.

40. Tabb, M.M., et al. 2003. Vitamin K2 regulation of bone homeostasis is mediated by the steroid and xenobiotic receptor SXR. J. Biol. Chem. 278:43919-43927.

41. De Bosscher, K., Vanden Berghe, W., and Haegeman, G. 2003. The interplay between the glucocorticoid receptor and nuclear factor-kappaB or activator protein-1: molecular mechanisms for gene repression. Endocr. Rev. 24:488-522.

42. Synold, T.W., Dussault, I., and Forman, B.M. 2001. The orphan nuclear receptor SXR coordinately regulates drug metabolism and efflux. Nat. Med. 7:584-590.

43. Rachez, C., and Freedman, L.P. 2000. Mechanisms of gene regulation by vitamin $\mathrm{D}(3)$ receptor: a network of coactivator interactions. Gene. 246:9-21.

44. Zhou, C., et al. 2004. Hyperforin, the active component of St. John's wort, induces IL-8 expression in human intestinal epithelial cells via a MAPKdependent, NF-kappaB-independent pathway. J. Clin. Immunol. 24:623-636.

45. Grun, F., et al. 2002. Benzoate X receptors alpha and beta are pharmacologically distinct and do not function as xenobiotic receptors. J. Biol. Chem. 277:43691-43697.

46. Livak, K.J., and Schmittgen, T.D. 2001. Analysis of relative gene expression data using real-time quantitative PCR and the 2(-Delta Delta C(T)) Method. Methods. 25:402-408. 